\title{
International Phonetic Association: Financial Statements
}

Year ended 31 December 1999

Income and Expenditure Account

\begin{tabular}{|c|c|c|}
\hline & $\begin{array}{l}1999 \\
\text { Stf }\end{array}$ & $\begin{array}{l}1998 \\
\text { Stf }\end{array}$ \\
\hline \multicolumn{3}{|l|}{ Income } \\
\hline Members' Subscriptions & 6595 & 3987 \\
\hline Life Membership Subscriptions & 1170 & 1241 \\
\hline Institutions' Subscriptions & 6455 & 6998 \\
\hline Advertising & 173 & -.-- \\
\hline Publications & 204 & 75 \\
\hline Examination Fees & 220 & \\
\hline \multirow[t]{2}{*}{$\begin{array}{l}\text { Royalties } \\
\text { Interest Earned }\end{array}$} & $\begin{array}{l}504 \\
390\end{array}$ & $\begin{array}{l}48 \\
647\end{array}$ \\
\hline & 15711 & 12996 \\
\hline \multirow{7}{*}{$\begin{array}{l}\text { Expenditure } \\
\text { Secretarial Services } \\
\text { Printing } \\
\text { Postage and stationery } \\
\text { Accountancy } \\
\text { Bank Charges } \\
\text { Unrealised Loss [Gain] on Foreign Exchange }\end{array}$} & & \\
\hline & 5601 & 6000 \\
\hline & $-\ldots-$ & 3318 \\
\hline & 471 & 1137 \\
\hline & 610 & ------ \\
\hline & $\begin{array}{c}23 \\
178\end{array}$ & {$\left[\begin{array}{c}191 \\
25\end{array}\right]$} \\
\hline & 6883 & 10621 \\
\hline Surplus [loss] for year & 8828 & 2375 \\
\hline Surplus Brought Forward & 28076 & 25701 \\
\hline Surplus Carried Forward & 36904 & 28076 \\
\hline Surplus Carried Forward & 36904 & 28076 \\
\hline
\end{tabular}

Approved by and on behalf of International Phonetic Association John Esling - Secretary

Ailbhe Ní Chasaide - Treasurer 1 November 2000. 
Balance Sheet

31 December 1999

\author{
Current Assets \\ National Westminster Bank: \\ Current Account \\ Business Reserve Account \\ Capital Reserve Account \\ Bank of Ireland \\ Current Account \\ Girobank \\ Leeds University Account \\ Computer Equipment \\ Cost \\ Net Book Value
}
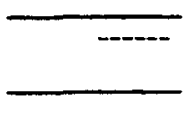

16970

7623

3948

3879

13158

12837

1336

1570

725

832

36904

28076

Total Assets

$\underline{36904}$

28076

Represented by:

General Fund

36904

28076

Approved by and on behalf of International Phonetic Association John Esling - Secretary

Ailbhe Ní Chasaide - Treasurer 1 November 2000.

\section{REPORT OF THE ACCOUNTANTS}

In accordance with instructions given to us, we have prepared, without carrying out an audit, the financial statements set out on pages 2 and 3 from the accounting records of International Phonetic Association and from information and explanations supplied to us.

Mc Closkey \& Co

Chartered Accountants

44 York Road

Rathgar

Dublin 61 November 2000. 